\title{
Making the most of daylight in town planning
}

\author{
Bengt Sundborg \\ Department of Architecture, Royal Institute of Technology. Sweden \\ E-mail: basun@kth.se
}

\begin{abstract}
Making the most of daylight in town planning is one of the important ingredients in the attempts for the sustainable city. Exactly 150 years ago Ildefons Cerdà presented his great work "Teoría General de la Urbanización" including methods for taking care of sunlight. However, with modern software, the possibilities to do comprehensive preparations are much better. This paper presents an urban typology considering daylight with basic geometric forms, shapes and patterns. Later this will be elaborated more in detail. The research includes three steps; choosing typical alternatives for settlements and designing some new principle urban solutions, calculations and evaluations of the alternatives considering especially energy saving. The quality and the quantity of daylight are dependent of the geometry of the urban spaces. That means the volumes for the buildings as well as the empty spaces in between. The accessibility for diffuse daylight from the sky and for direct rays from the sun is measurable by computer calculations where the sun angles and the skylight from the hemisphere are simulated. Relevant parameters are height, width and length. In a settlement with a high urban density it is more difficult to distribute daylight than in a settlement with low density. However, the economy for exploitations is also worse with lower density. Therefore, the comparisons between different settlements are with the same density. The orientation of the settlements according to the compass is of crucial importance looking to the direct sunlight and the shadows. How the local environment with parks, water, mountains and specific landmarks in the surroundings also affects the daylight distribution is included.
\end{abstract}

Keywords: Daylight, energy saving, typology, urban design, climate

\section{Introduction}

Making the most of daylight in town planning is one ingredient in the the sustainable city. Exactly 150 years ago Ildefons Cerdà presented his great work "Teoría General de la Urbanización" including methods for taking care of sunlight. However, with modern software, the possibilities to do comprehensive preparations are much better. This paper presents a first step against an urban typology considering daylight with basic geometric forms, shapes and patterns.

The strict linguistic interpretation of Urban Morphology is the knowledge of the forms in an urban settlement, which are mostly the forms of buildings, blocks and street patterns. However the actual definitions for the topic are much broader as all professionals know. But just in the search for adaptations to the sun the strict geometric approach is relevant. That because the sun angles and the variations of daylight during the day, as well as the year, in addition to the geographical latitudes on earth together with the geometrical forms in the city are the shaper of the fields of shadows and sunshine. An urban morphology for daylight consists of clean geometric forms, shapes and patterns in the city free from history, styles and social processes. In exploring and inventing 
successful new shapes for daylight, such a liberated approach could be seen as necessary.

The geometry of the street grid, together with the height of the buildings, is important for the amount of available daylight in towns. The Case Study in my licentiate thesis (Sundborg, 2016) had a basic method which is used directly, or adapted, in my actual research into different urban settlements. I have done calculations and simulations for three different street alternatives.

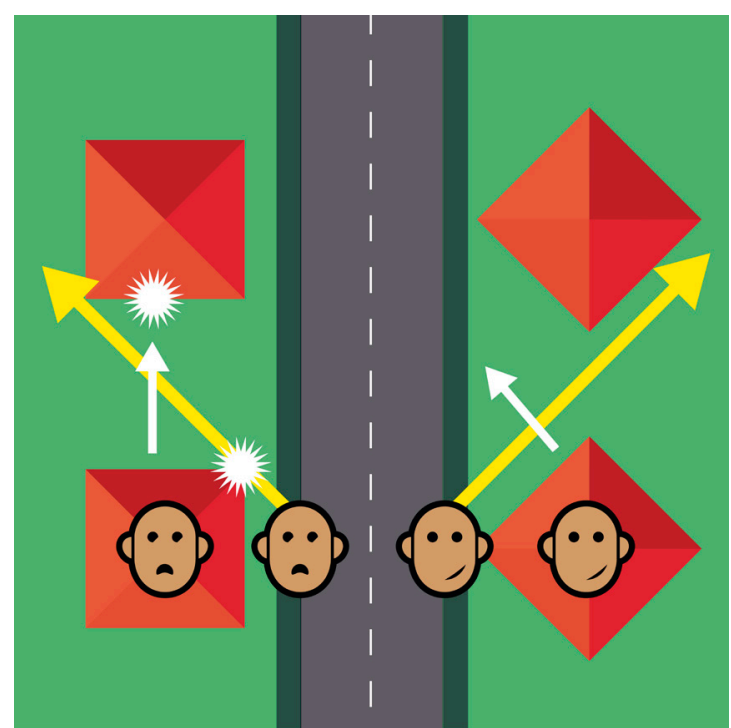

Figure 1. The two obliquely positioned houses to the right have lighter apart-ments then the paralleled positioned houses to the left (IIl. R. Manson, 2017).

Daylight computer simulation models have been performed in order to compare, contrast and calculate the savings of energy for the three types of settlements. With the same spacing and the same exploitation coefficient, it is possible to save energy for electric light through alternative geometrical solutions of the block, the street and the buildings compared to the higher energy use in the conventional layout typology.

The savings depend on good town planning where the daylight is accessible for longer periods of time during the day, both indoors and outdoors. That is when periods of use for electric light will decrease. This research is one of the first studies which evaluate the savings in energy with electric lighting due to the use of daylight in urban planning. The three different patterns for street layouts have been evaluated regarding energy consumption. For example, with straight streets it is possible to save approximately $11 \%$ of the electric energy for the exterior lighting compared to a bending street during twilight. The consumption calculations have approximately the same values in Helsinki, Oslo and Stockholm, which depends on the similarity in latitude.

$11 \%$ is the value for a straight street with a specific geometry. With more articulated bending, or comparisons between streets with buildings higher than five stories, the savings for a straighter street will be higher. The energy savings are not so great that they alone can justify a specific street type. A number of other factors must also be considered, such as architectural style, uniformity and the building system. The savings from positively affected streets, the straight and the improved bended street, has other advantages so the feasibility is good.

\section{Evaluations of Urban Settlements}

Different ways to handle problems related to exploitation was first described in a more detailed structure by the Spanish-Catalan theorist and urban planner Ildefonso Cerda. Later, Raymond Unwin analyzed and compared different solutions throughout the literature. Many others, who came after them, such as the famous architects Le Corbusier and Frank Lloyd Wright, continued and extended this valuable intellectual debate. In Urban Space and Structure, edited by Leslie Martin and Lionel March, they give a good overview over that debate. Especially instructive is the chapter 1:1 (Martin, 1972) with alternative discussions from Manhattan and London. It is also very stimulating in how it develops the viewpoint to new alternatives. Martin emphasised the importance of well described parameters around access, free space, natural lighting, views, etc. 

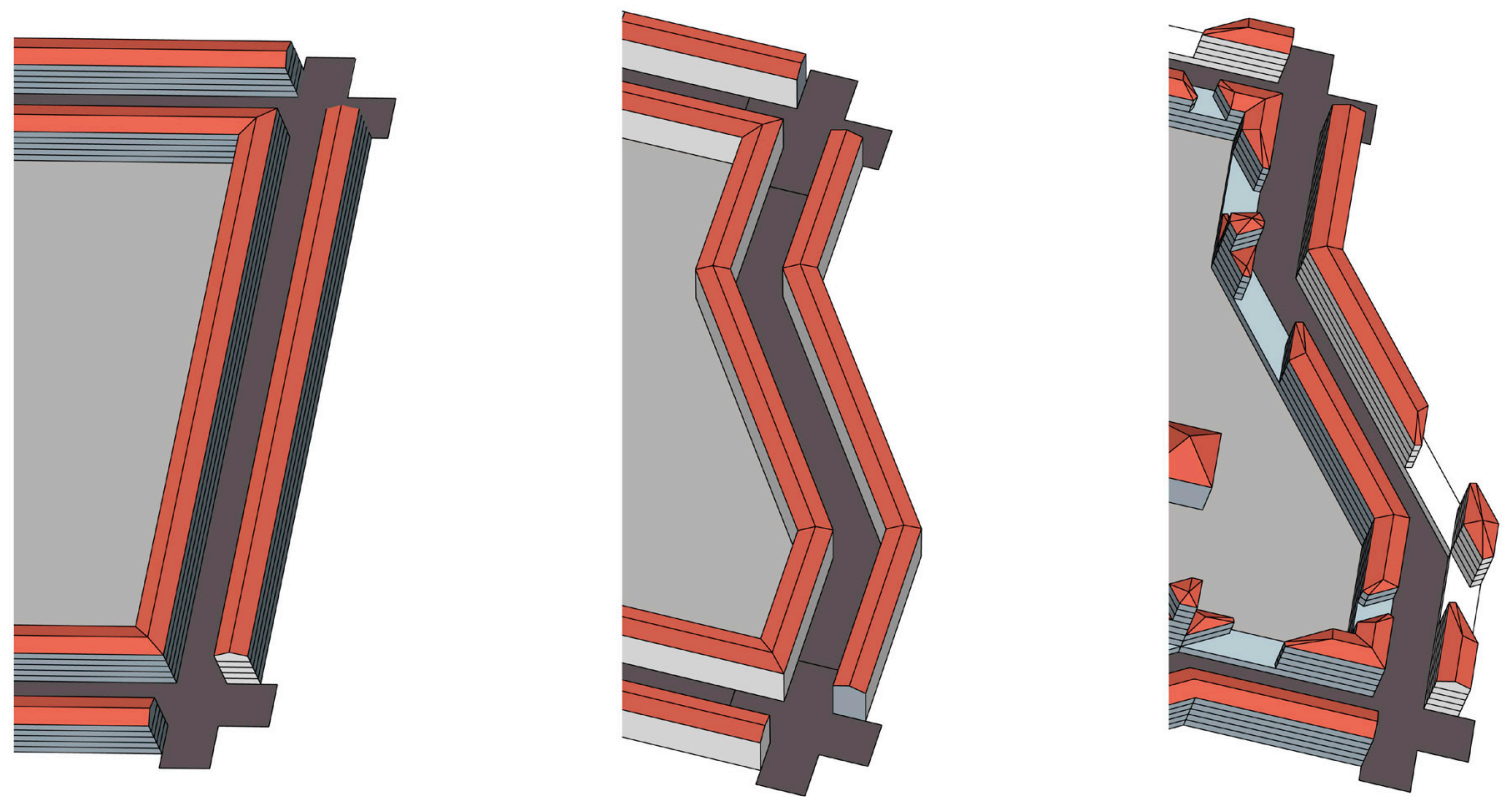

Figure 2. Three different street layouts have been evaluated regarding energy consumption (IIl. R. Manson, 2017).

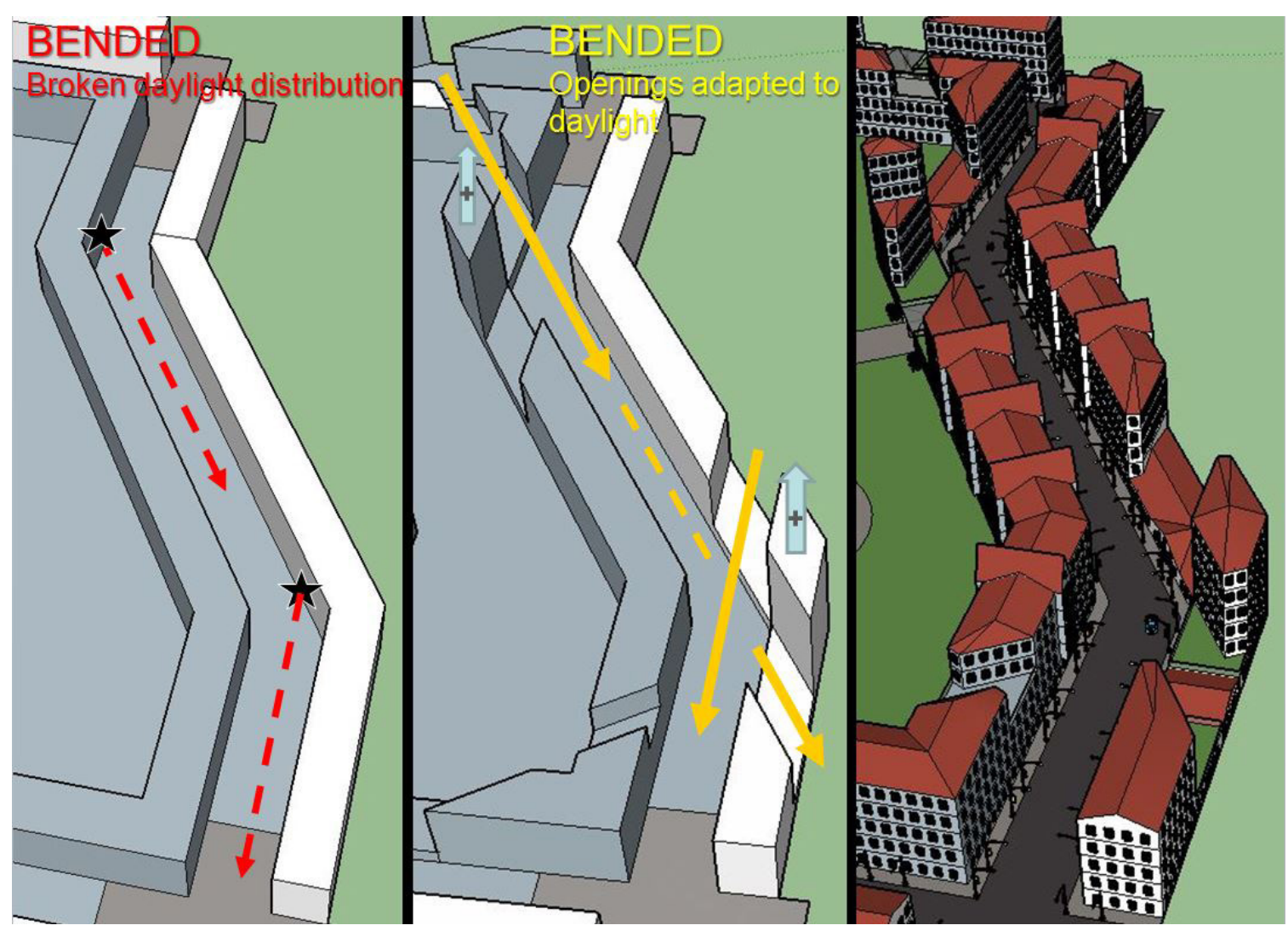

Figure 3. Daylight adaptations in the bends of a street regarding the heights of the buildings (IIl. Sundborg, 2015). Those adaptations resulted in the third street layout alternative see fig 2. 
Strategies, Principles and Regulations for a Good Urban Design Regarding Daylight

One of the earlier studies in this topic which is worthwhile to mention is Paul Little fair's classic guide from 1993 which has been recently revised and updated (Littefair, 2011). A recently published report (Rode et al., 2014) shows how important the energy aspect is today. In the Nordic countries, daylight is especially difficult to handle with respect to its great variation diurnally and over the course of the year. A handbook on "Daylight in urban settlements" based on the experiences from practical town planning has been written in Swedish (Sundborg, 2010).

The development of "good examples" can be strategies, principles and regulations for a good urban design in regards to daylight. Strategies could include orientate of a building according to the compass. Principles can be to avoid acute corners of buildings. Regulations can be to specify the minimum angle from a basement floor of a building which must have direct access to the sky. The examples in my research will mostly be adapted to the Scandinavian latitudes where the most common problem is to develop places with good daylight, not the opposite problem in other climates which is to create shadows.

\section{Many aspects and parameters}

To analyze and evaluate existing and proposed settlements, one needs well-defined and descriptive measures and approaches. The initial research includes choosing the most typical alternatives and even designing some new principle urban solutions. Then the calculations and evaluations of the alternatives can start. All morphological facts mentioned below will impact the daylight: The savings in the urban spaces are in different levels in the settlements as:

1- Network. Different street grids have different efficiencies for daylight distribution.

2- Street. Different street types have different efficiencies for daylight distribution.

3- Block. Different types of blocks have different efficiencies for daylight distribution.
4- Building. Different types of buildings and building details as windows have different efficiencies for daylight distribution.

The savings are dependent of the conditions in the urban spaces:

1 - The geometry in $3 \mathrm{D}$ regarding the spaces for buildings and the empty spaces in between. 2- The accessibility for diffuse daylight from the sky and for direct rays from the sun is measurable by i.e. calculations in computer models where the sun angles and the skylight from the hemisphere are simulated. Relevant parameters are height, width and length.

3 - The density. In a settlement with a high urban density it is more difficult to distribute daylight than in a settlement with low density. However, the economy for exploitations is also worse with lower density. Therefore it is important to do a comparison between different settlements with the same density.

The orientation of the settlements, according to the compass.

4- Special features in the local environment. Parks, water, mountains and specific landmarks in the surroundings which can affect the daylight distribution.

1- The savings in the indoor spaces are dependent of:

2- The actual conditions in the urban spaces, see above.

3- The geometry in 3D for the actual room.

4- The size and the localization of the windows.

The orientation of the room and the windows, according to the compass.

Using other strategic techniques, variations in the height of the buildings and calculating the placement of the openings between the buildings, can improve the daylight distributions.

\section{The Structural Approach - A Proposal}

A typology for daylight analysis is under development. The different possible alternatives for urban settlements are huge. The alternatives must be selected well, simplified and then structured in a logic and transparent way. One natural approach is to divide the alternatives after the urban scale from Network over Street and Block to Building and details as Windows. The impacts of daylight will be investigated in the exteriors as well as the interiors. 


\section{Network.}

The street grid consists of its streets and blocks. Sometimes it can be organic with bending streets often along the height curbs in the terrain. The street grids can also be geometric with $\mathrm{radial} /$ diagonal and tangential/circular streets. The very common rectilinear street grids with right angled blocks has straight streets which are good for the distribution of daylight.

\section{Street.}

Streets can be straight or bended in the horizontal level. It can also bend in the vertical level shaping a convex or a concave street line.

\section{Block.}

The city block can be built in many different ways. In the research, the focus is on variations in two types: groups of tower blocks and perimeter blocks.

- Groups of Tower Blocks: One of many important aspects to notice is if the facades are parallel or obliquely positioned to each other. The groupings can be made in different regular geometric patterns or in more random arrangements. In the study "Urban Form, Density and Solar Potential" (Cheng et. al., 2006) some combinations was tested. The research team concluded advantages for randomly positioned buildings compared to repetitive patterns.

I don't believe in that due to several reasons. My hypothesis is that it always exist one strategy which is better than all random solutions. The only exception is the random alternative which happens to be identical to the strategy. The further research should hopefully give the answer.

-Perimeter Blocks: The typical right angled block, the zero alternative in figure 4 below, are shaped in squares without variations in height and no openings. The alternative can vary setting the block length, the amount of stores or the depth of the houses as parameters. All this parameters affects the exploitation and the distribution of daylight. Such compare have been done in earlier studies. For practical use it is more interesting to compare variations in shape within a given exploitation.
Alternative $A$ is a transformation of alternative 0 with less building area in the dark corners of the block depending on another distribution of the heights of the single buildings.

Alternative $\mathrm{C}$ is like alternative 0 but with chamfered corners both against the street (as Cerdà once proposed) and the courtyard.

Alternative B has both chamfered corners and the variation in heights.

The alternatives D, E, F and G has all the same exploitation which is lower than the first four alternatives depending of that each alternatives has two openings between the streets and the courtyard.

$\mathrm{E}$ and $\mathrm{G}$ has the openings in the corner two improve the daylight distribution in the darkest place in the courtyard. D and F have the openings in the middle of the facades which are probably the most common solution. The reason for two openings in the alternatives not only one is to evaluate how much the low angled daylight passing through both openings can improve the conditions within the courtyard and further to similar blocks in straight lines in the street grid as a whole. D and $\mathrm{E}$ have openings combined with chamfered corners.

-The Orientation and the Extent of the Perimeter Block: It is interesting to expand the study from diffuse daylight to even direct sunlight. Within that expansion it is important to also consider the consequences of perimeter blocks extent to a rectangular form.

-The Orientation and the Groups of Tower Blocks: The orientation has more importance for the direct sunlight in groups of tower blocks than in more dense settlements as in the perimeter blocks. So this will also be investigated.

\section{Building.}

The buildings form also affects the distribution of daylight. The facades can be plain, convex and concave or folded in different ways. The roofs usually have forms according to the established building types with some common alternatives.

The corner of the building has a large effect on the daylight distribution. The common 
geometries are round, chamfered or with an angle which is acute, obtuse or perpendicular. Occasionally, even more complicated shapes are used. Arcades and terraces are also interesting ways to shape the building in a practical way, which affect the daylight distribution.
Specific proposals combining different features.

To obtain "really good daylight" results would normally require a set of efforts cooperating together, not only a single measure. Such combined solutions, both proposals and existing buildings are interesting to evaluate in more detailed studies.

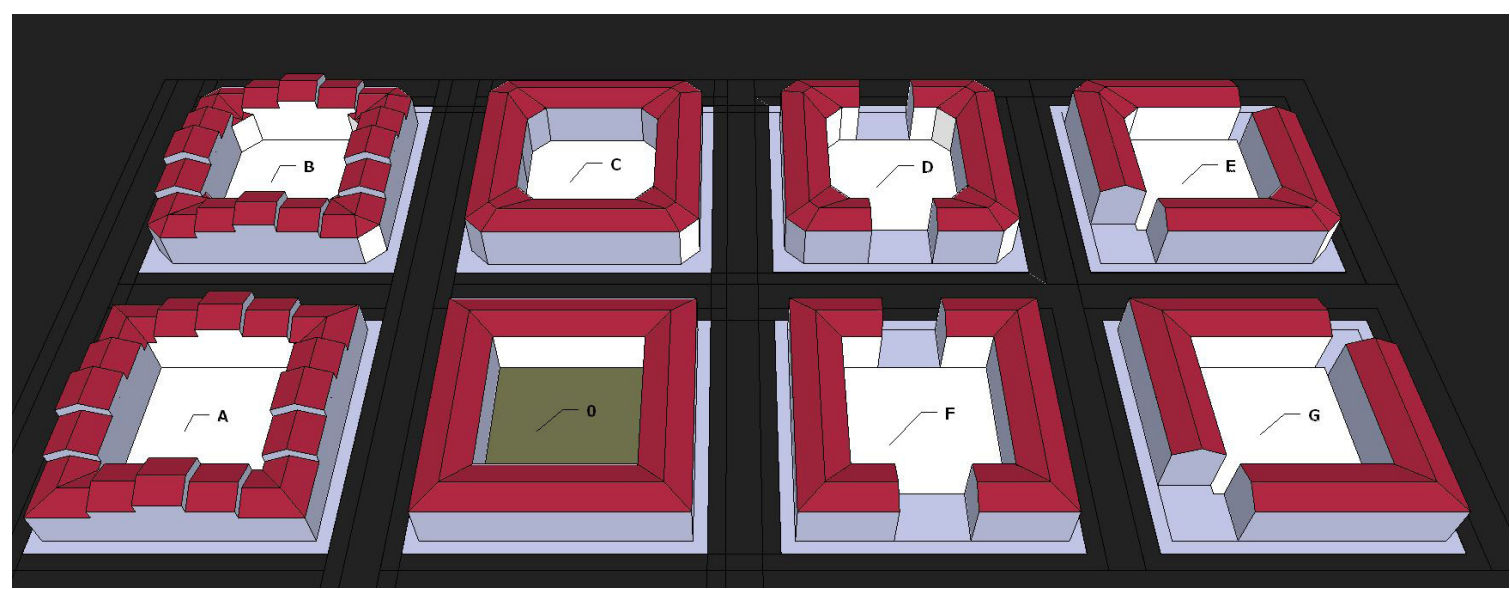

Figure 4. Perimeter Blocks. Variations in height, corner and openings within a given exploitation (IIl. Sundborg, 2017).

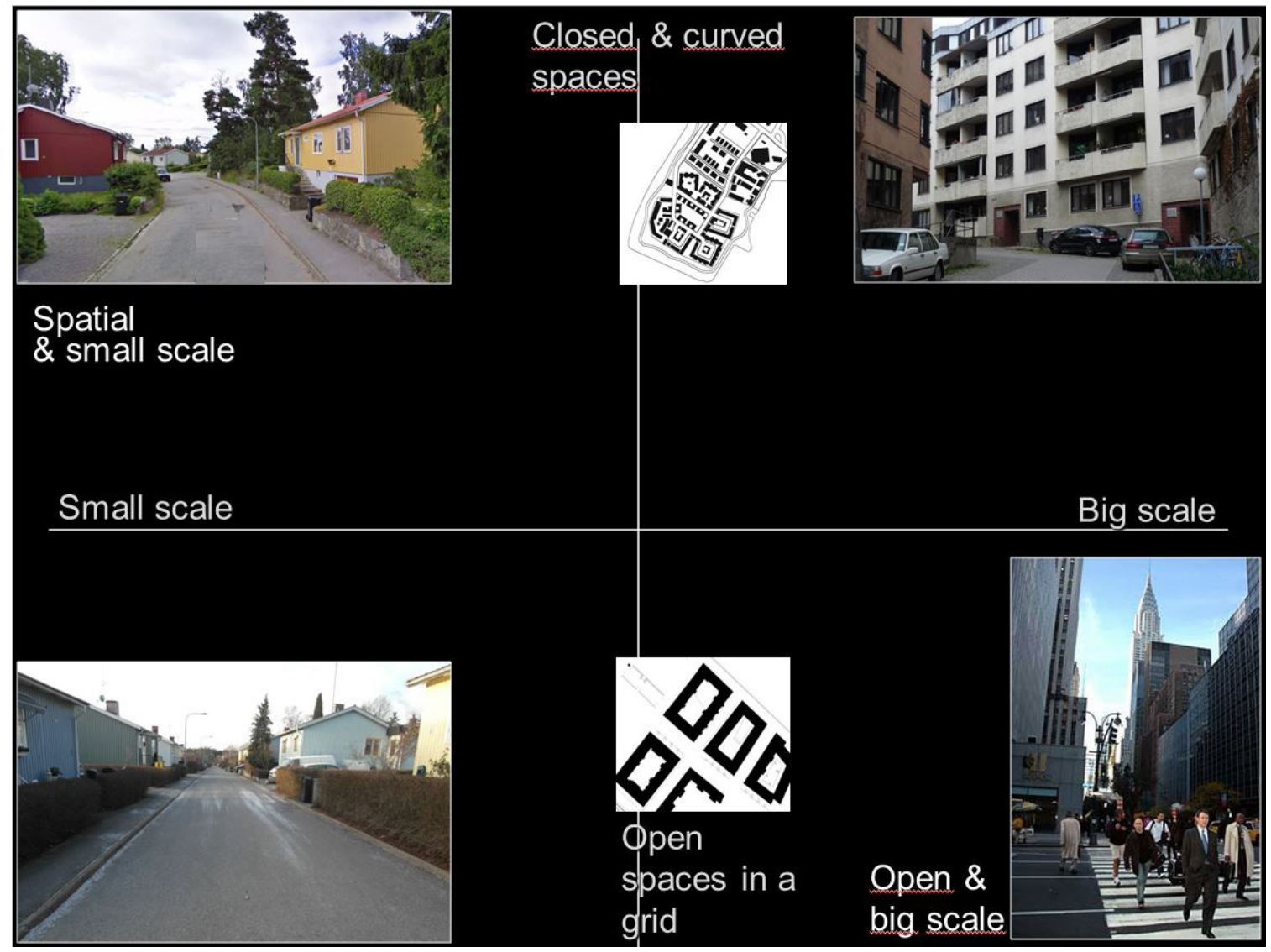

Figure 5. A compact and dense settlement requires more adaptations to daylight as straight facades along straight streets than one with a lower density (IIl. Sundborg, 2012). 


\section{Details as window.}

The windows deliver almost all natural light indoors. Placement and direction of the windows are, therefore, of crucial importance. Different features, such as protruding or not protruding frames, is also relevant as well as bay windows and other arrangements of the windows.

\section{Urban Density and Daylight}

With increasing urban density the amounts of daylights decrease. A special look to the urban density is therefore of crucial interest for researchers in urban daylight. A paper in "Nordisk Arkitekturforskning" (Berghauser Pont \& Marcus, 2014) summarizes common urban density measurements and describes their shortcomings. The authors propose the Space Mate method, which includes a multi-variable definition of density that captures important morphological qualities such as accessible and perceived density that otherwise can result in a focus in abstract numbers. In the method, three geometrical properties of buildings are handled together:

Density expressed as a floor space index (FSI), ground coverage, and number of floors. An interesting paper brings urban space together with Space Mate and shows how Martin and March's analysis can develop a theoretical explanation for Berghauser Pont and Haupt's empirical findings (Steadman, 2013). Steadman also introduces two additional variables: depth of buildings in plan, and cutoff angles describing the distances by which buildings are separated. For daylight studies, that addition is of great value.

\section{Final Comments}

The PhD Report (planned to 2019-06-03) will contain evaluations of many different settlements and, hopefully, also include results for single buildings. A long-term goal for this research in its entirety is practical guidelines for "better" geometry in urban design, taking into consideration the effect of the sun and resulting daylight.

\section{References}

Berghauser Pont, M. \& Marcus, L. (2014) "Innovations in Measuring Density: From Area and Location Density to Accessible and Perceived Density" Nordisk Arkitekturforskning, number 2, 11-30.

Cheng, V., Steemers, K., Montavon, M. \& Compagnon, R. (2006) Urban Form, Density and Solar Potential, PLEA2006 - The 23rd Conference on Passive and Low Energy Architecture, Geneva, Switzerland.

Littefair, P. J. (2011) Site layout planning for daylight and sunlight: a guide to good practice (BRE, Building Research Establishment, IHS BRE Press, Watford).

Martin, L. (1972), "The grid as generator", in Urban Space and Structures, eds. Martin, L. \& March, L. (Cambridge University Press, Cambridge) pp 6-27

Rode, P., Keim, C., Robazza, G., Viejo, P. and Schofield, J. (2014) Cities and energy: urban morphology and heat energy demand (LSE, London School of Economics, Cities and EIFER, European Institute for Energy Research, Karlsruhe Institute of Technology, London).

Steadman, P; (2013) Density and built form: integrating 'Spacemate' with the work of Martin and March. Environment And Planning B: Planning \& Design, volume 40, pp. 1-18.

Sundborg, B. (2010) Ljus i bebyggelsen (AB Svensk Byggtjänst, Stockholm).

Sundborg, B. (2016) Energy Savings by Using Daylight for Basic Urban Shapes - With a Case Study of Three Different Street Types KTH Royal Institute of Technology, KTHpress, Stockholm. 